\title{
Intracellular Astrocyte Calcium Waves In Situ Increase the Frequency of Spontaneous AMPA Receptor Currents in CA1 Pyramidal Neurons
}

\author{
Todd A. Fiacco and Ken D. McCarthy \\ Department of Pharmacology, University of North Carolina at Chapel Hill, Chapel Hill, North Carolina 27599-7365
}

\begin{abstract}
Spontaneous neurotransmitter release and activation of group I metabotropic glutamate receptors (mGluRs) each play a role in the plasticity of neuronal synapses. Astrocytes may contribute to short- and long-term synaptic changes by signaling to neurons via these processes. Spontaneous whole-cell AMPA receptor (AMPAR) currents were recorded in CA1 pyramidal cells in situ while evoking $\mathrm{Ca}^{2+}$ increases in the adjacent stratum radiatum astrocytes by uncaging $\mathrm{IP}_{3}$. Whole-cell patch clamp was used to deliver caged $\mathrm{IP}_{3}$ and the $\mathrm{Ca}^{2+}$ indicator dye Oregon green BAPTA- 1 to astrocytes. Neurons were patch-clamped and filled with Alexa 568 hydrazide dye to visualize their morphological relationship to the astrocyte. On uncaging of $\mathrm{IP}_{3}$, astrocyte $\mathrm{Ca}^{2+}$ responses reliably propagated as a wave into the very fine distal processes, synchronizing $\mathrm{Ca}^{2+}$ activity within astrocyte microdomains. The intracellular astrocyte $\mathrm{Ca}^{2+}$ wave coincided with a significant increase in the frequency of AMPA spontaneous EPSCs, but with no change in their kinetics. AMPAR current amplitudes were increased as well, but not significantly $(p=0.06)$. The increased frequency of AMPAR currents was sensitive to the group I mGluR antagonists LY367385 and 2-methyl-6-(phenylethynyl)-pyridine, suggesting that (1) astrocytes released glutamate in response to IP ${ }_{3}$ uncaging, and (2) glutamate released by astrocytes activated group I mGluRs to facilitate the release of glutamate from excitatory neuronal presynaptic boutons. These results extend previous studies, which have shown astrocyte modulation of neuronal activity in vitro and suggest that astrocyte-to-neuron signaling in intact tissue may contribute to synaptic plasticity.
\end{abstract}

Key words: acute hippocampal slice; $\mathrm{IP}_{3}$ uncaging; glutamate; extrasynaptic; $\mathrm{mGluR}_{1 \mathrm{a}} ; \mathrm{mGluR}_{5}$

\section{Introduction}

Spontaneous release of glutamate by neuronal synaptic boutons is a $\mathrm{Ca}^{2+}$-dependent process that results in the generation of AMPA- and NMDA-receptor-mediated spontaneous EPSCs (sEPSCs). Spontaneous transmitter release plays a role in the maintenance of synaptic morphology (McKinney et al., 1999), mediates short-term plasticity (Emptage at al., 2001), and is upregulated in a form of long-term potentiation (LTP) (Malgaroli et al., 1995, Fitzjohn et al., 2001a). Factors that modulate the frequency of spontaneous transmitter release may contribute to short- and long-term synaptic changes.

Group I mGluRs are linked to the production of inositol triphosphate $\left(\mathrm{IP}_{3}\right)$ and $\mathrm{Ca}^{2+}$ release from internal stores (for review, see Anwyl, 1999). Calcium mobilization and protein synthesis triggered by group I mGluRs are involved both in longterm depression (LTD) (Bortolotto et al., 1999; Fitzjohn et al., 2001b) and in the induction of stable LTP (Manahan-Vaughan

Received Aug. 29, 2003; revised Nov. 19, 2003; accepted Nov. 19, 2003.

This work was supported by National Institute of Neurological Disorders and Stroke Grant NS-20214. We thank Dr. Wolfgang Nett for his technical assistance, Dr. Paul B. Manis for valuable discussions regarding synaptic physiology, and Biljana Djukic for proofreading this manuscript.

Correspondence should be addressed to Ken D. McCarthy, Department of Pharmacology, 1138 Mary Ellen Jones Building CB 7365, University of North Carolina at Chapel Hill, Chapel Hill, NC 27599-7365. E-mail: kdmc@med.unc.edu.

DOI:10.1523/JNEUROSCI.2859-03.2004

Copyright $\odot 2004$ Society for Neuroscience $\quad$ 0270-6474/04/240722-11\$15.00/0 and Reymann, 1997; Cohen et al., 1998; Bortolotto et al., 1999). Activation of group I mGluRs induces long-term changes in the morphology of dendritic spines (Vanderklish and Edelman, 2002) and regulates the frequency of the spontaneous release of neurotransmitter (Rodriguez-Moreno et al., 1998; Cartmell and Schoepp, 2000; Fitzjohn et al., 2001). The timing and strength of group I mGluR activation may code for the direction of longterm functional and morphological synaptic changes.

Metabotropic GluRs are generally localized beyond synaptic specializations (extrasynaptically) (Cartmell and Schoepp, 2000). They are activated in situations in which glutamate diffuses beyond the synaptic cleft (i.e., during increased neuronal activity) (Scanziani et al., 1997; Kullmann, 1999; Diamond and Jahr, 2000; Isaacson, 2000). Group I mGluRs may also sense glutamate released from extrasynaptic sources. A source of extrasynaptic glutamate that has received a considerable amount of interest in recent years is provided by astrocytes. Astrocyte processes ensheathe neuronal synapses (Ventura and Harris, 1999) and release glutamate in a $\mathrm{Ca}^{2+}$-dependent manner in vitro (Araque et al., 1998, 2000; Parpura and Haydon, 2000). Astrocytes increase the number of mature, functional synapses on neurons during development (Ullian et al., 2001) and are required for synaptic maintenance in vitro (Beattie et al., 2002).

We have measured an increased frequency of AMPA sEPSCs in CA1 pyramidal cells in situ after evoking an intracellular $\mathrm{Ca}^{2+}$ wave in an adjacent astrocyte by uncaging $\mathrm{IP}_{3}$. The elevated fre- 
quency of neuronal AMPA sEPSCs lasted $\sim 48 \mathrm{sec}$ and was repeatable during subsequent $\mathrm{IP}_{3}$ uncagings in the astrocyte. AMPA current kinetics were unchanged, suggesting that glutamate released by astrocytes in situ does not diffuse into neuronal synaptic clefts to activate postsynaptic AMPARs directly. The specific group I mGluR antagonists LY367385 and 2-methyl-6(phenylethynyl)-pyridine (MPEP) blocked the effect, suggesting that astrocytes increase the probability of the spontaneous release of glutamate by activating group I mGluRs on excitatory afferent terminals. These observations suggest that astrocytes play an important role in the maintenance and plasticity of neuronal synapses by stimulating group I mGluRs and modulating the frequency of spontaneous neurotransmitter release.

\section{Materials and Methods}

Hippocampal slice preparation. C57BL/6J or GFAP-enhanced green fluorescent protein (eGFP) mice (The Jackson Laboratory, Bar Harbor, ME) aged $10-15 \mathrm{~d}$ were anesthetized by isoflurane inhalation. The brains were rapidly removed after decapitation and submerged into $0-4^{\circ} \mathrm{C}$ slicing buffer containing the following: $125 \mathrm{~mm} \mathrm{NaCl}, 10 \mathrm{~mm}$ glucose, $1.25 \mathrm{~mm}$ $\mathrm{NaH}_{2} \mathrm{PO}_{4} \times \mathrm{H}_{2} \mathrm{O}, 26 \mathrm{~mm} \mathrm{NaHCO}_{3}, 2.5 \mathrm{~mm} \mathrm{KCl}, 3.8 \mathrm{~mm} \mathrm{MgCl}_{2}$, and 100 $\mu \mathrm{M}$ kynurenic acid bubbled with $95 \% \mathrm{O}_{2}$ and $5 \% \mathrm{CO}_{2}$. Brains were blocked into hemispheres and cut sagittally at a thickness of $300 \mu \mathrm{M}$ on a Leica (Bannockburn, IL) vibratome. During sectioning brains were kept submerged in $0-4^{\circ} \mathrm{C}$ oxygenated slicing buffer. Hippocampi were dissected out of each brain slice and incubated for $45 \mathrm{~min}$ in artificial CSF (ACSF) warmed to $35-36^{\circ} \mathrm{C}$ and bubbled continuously with $95 \% \mathrm{O}_{2}$ and $5 \% \mathrm{CO}_{2}$. The ACSF contained the following: $125 \mathrm{~mm} \mathrm{NaCl}, 10 \mathrm{~mm}$ glucose, $1.25 \mathrm{~mm} \mathrm{NaH}_{2} \mathrm{PO}_{4} \times \mathrm{H}_{2} \mathrm{O}, 26 \mathrm{~mm} \mathrm{NaHCO}_{3}, 2.5 \mathrm{~mm} \mathrm{KCl}, 2.5 \mathrm{~mm}$ $\mathrm{CaCl}_{2}, 1.3 \mathrm{mM} \mathrm{MgCl}_{2}$, and $100 \mu \mathrm{M}$ Trolox. After the incubation period slices were allowed to cool gradually to room temperature $\left(24-27^{\circ} \mathrm{C}\right)$ but always kept under vigorous oxygenation. Slices were placed into a recording chamber and continuously superfused with oxygenated ACSF. The stratum radiatum of field CA1 was visualized using an Olympus (Melville, NY) BX50WI fixed-stage upright microscope equipped with water-immersion objectives and differential interference contrast (DIC) optics. Individual astrocytes in CA1 stratum radiatum were initially identified by their location, size, and morphological characteristics (see Results). Classification of cells as either astrocytes or pyramidal neurons was later verified by their electrophysiological properties.

Whole-cell patch clamp of astrocytes and neurons. Pipettes were pulled from borosilicate glass on a Narishige (Tokyo, Japan) PP-83 two-stage vertical pipette puller and not fire-polished. Pipettes pulled for astrocytes had resistances of 11-12 $\mathrm{M} \Omega$ when filled with the internal solution, which contained the following: $130 \mathrm{~mm} \mathrm{~K}$-gluconate $130,4 \mathrm{~mm} \mathrm{MgCl}$, $10 \mathrm{~mm}$ HEPES, $10 \mathrm{~mm}$ glucose, $1.185 \mathrm{~mm} \mathrm{Mg}$-ATP, $10.55 \mathrm{~mm}$ phosphocreatine, and $0.1315 \mathrm{mg} / \mathrm{ml}$ creatine phosphokinase, brought to $\mathrm{pH} 7.3$ by $\mathrm{KOH}$. Also included in the astrocyte solution was $200 \mu \mathrm{M}$ calciumindicator dye Oregon green BAPTA-1 (OGB-1) and $400 \mu \mathrm{M}$ caged $\mathrm{IP}_{3}$ (Molecular Probes, Eugene, OR). Neuronal pipettes had resistances of 4.6-5.3 $\mathrm{M} \Omega$ when filled with a solution containing the following (in $\mathrm{mm}$ ): $145 \mathrm{~K}$-gluconate, $2 \mathrm{MgCl}_{2}, 10 \mathrm{HEPES}, 4 \mathrm{Mg}$-ATP, 14 phosphocreatine, and 0.25 EGTA, brought to $\mathrm{pH} 7.3$ with $\mathrm{KOH}$. Neuronal pipettes also included $200 \mu \mathrm{M}$ Alexa Fluor 568 hydrazide dye. Pipettes were advanced through the tissue slice toward individual cells under positive backpressure to prevent debris from clogging the pipette tip. Liquid junction potentials were compensated using the pipette offset feature of the amplifier. After establishing the whole-cell configuration, liquid junction potentials were not corrected. Whole-cell patch-clamp recordings were performed at room temperature using an Axopatch 200B amplifier and PCLAMP 8.1 software (Axon Instruments, Union City, CA).

The patch procedure was modified somewhat for astrocytes to maximize astrocyte health after removal of the patch pipette and to obtain strong, repeatable $\mathrm{IP}_{3}$ uncaging $\mathrm{Ca}^{2+}$ responses. Astrocytes were patched using very small pipette tips to limit damage to the cell membrane and diffusion of essential signaling molecules out into the pipette. The duration of the whole-cell configuration was also important for maintaining cell viability and limiting dilution of essential intracellular components: just long enough to measure the electrophysiological characteristics $(<3$ $\mathrm{min}$ ). Astrocytes rested at $-85.1 \pm 0.5 \mathrm{mV}$ and had input resistances of $10.2 \pm 1.7 \mathrm{M} \Omega(n=30$ cells $)$. They exhibited passive currents when stepped from -180 to $+80 \mathrm{mV}$ in $20 \mathrm{mV}$ increments (see Results). A test pulse of $-5 \mathrm{mV}$ was included after each step to monitor changes in access resistance. Astrocyte current signals were low-pass-filtered at $2 \mathrm{kHz}$ and digitized at $100 \mathrm{kHz}$ via a Digidata 1200 (Axon Instruments) interfaced to an IBM-compatible personal computer. A smooth, stable off-cell and formation of an outside-out patch suggested minimal damage to the cell membrane during the patch-clamp procedure. $\mathrm{IP}_{3}$ was uncaged by a single $10 \mathrm{msec}, 30 \mathrm{~mW}$ pulse from a Coherent UV laser (Santa Clara, CA) fitted with a Chroma $360 \mathrm{~nm}$ bandpass filter, a UV filter, and two 1.0 neutral density filters. Filters were necessary to work within the normal power range of the laser $(>3 \mathrm{~mW})$ because at minimum power the laser is unstable and emits pulses of variable (unknown) amplitude. With filters in, a minimum power could be reached within the normal working range of the laser $(\sim 15 \mathrm{~mW})$, which is insufficient to uncage $\mathrm{IP}_{3}$ in astrocytes. For control experiments, the light filters were removed to know the precise timing when the flash of UV light was applied. Without the filters in, even at minimum laser power the intensity of the beam is so high that it creates a "light artifact" that is detected by the confocal microscope and clearly visible in the line scans. This was necessary because it is not possible otherwise to mark when the pulse of UV light is applied during line scans using our system.

The general electrophysiological features and spontaneous whole-cell currents of neurons were recorded while Alexa 568 dye diffused into dendritic compartments. Neurons rested at $-59.9 \pm 0.6 \mathrm{mV}$ with input resistances of $349.3 \pm 24 \mathrm{M} \Omega(n=30$ cells $)$ and seldom fired spontaneous action potentials. Single action potentials could be produced reliably by injecting $200 \mathrm{pA}$ of positive current for $10 \mathrm{msec}$. Access resistances were checked before and after current recordings to make sure consistent access was maintained. In recordings of spontaneous currents, IPSCs were eliminated by holding the neurons at $-70 \mathrm{mV}$, the calculated equilibrium potential for $\mathrm{Cl}^{-}$ions under our imposed conditions. Because the cell was never depolarized sufficiently to remove $\mathrm{Mg}^{2+}$ block of NMDA receptors, all sEPSCs recorded were AMPAR-mediated. To verify this, $\quad 10 \mu \mathrm{M}$ 2,3-dihydroxy-6-nitro-7-sulfonyl-benzo[f]quinoxaline (NBQX), a specific AMPAR antagonist, was added to the extracellular solution. NBQX completely blocked all sEPSCs (data not shown). To check that the currents "evoked" by uncaging $\mathrm{IP}_{3}$ in adjacent astrocytes were mediated by AMPARs, NMDA receptor currents were isolated so that their kinetics could be compared with those of AMPA currents. NMDA receptor currents were isolated by switching to $\mathrm{Mg}^{2+}$-free ACSF that contained $10 \mu \mathrm{M}$ NBQX. AMPA sEPSCs were low-pass-filtered at 2 $\mathrm{kHz}$ with a sampling interval of $5 \mathrm{kHz}$ per signal.

Considerable effort was made to remain consistent with regard to selection of neuron-astrocyte pairs throughout this study, because different regions of the neuronal dendritic tree harbor different numbers and distributions of receptors (Pettit and Augustine, 2000; Megias et al., 2001). Neuron-astrocyte pairs were carefully selected so that the neuronal apical dendrite was in the same optical plane as the astrocyte and its processes (see Fig. $7 a$; see also Figs. $5 a, 6 a$ ). Thus, neuron-astrocyte pairs were imaged using single optical sections $\leq 1.42 \mu \mathrm{m}$ thick using an Olympus LSM-GB200 argon/krypton confocal microscope. Astrocytes patched with OGB-1 appeared green, and neurons patched with Alexa 568 appeared red. Both dyes were excited by the $488 \mathrm{~nm}$ argon line (using a $500 \mathrm{~nm}$ dichroic filter) and emission was collected at $>515 \mathrm{~nm}$. Average fluorescence intensities were measured in astrocytes from analysis boxes placed over cell bodies and/or processes. These were digitized ( 8 bit), normalized to baseline level $\left(F / F_{0}\right)$, and plotted over time. Increases in $\mathrm{F} / \mathrm{F}_{0}$ indicate increases in $\mathrm{Ca}^{2+}$ concentration.

Bulk loading of astrocytes and dye coupling experiments. Slices were incubated for $50 \mathrm{~min}$ at $35^{\circ} \mathrm{C}$ in oxygenated ACSF that included $11 \mu \mathrm{m}$ calcium green 1 -AM ester dye and $0.07 \%$ pluronic acid (final DMSO concentration, $0.4 \%$ ). The $\mathrm{Ca}^{2+}$ green was sequestered almost exclusively by astrocytes as observed previously in hippocampal slices from mice (Nett et al., 2002). Single astrocytes in bulk-loaded slices were patched with $200 \mu \mathrm{m}$ OGB-1 $+400 \mu \mathrm{m}$ caged $\mathrm{IP}_{3}+1 \%$ neurobiotin for 
$<3$ min. Slices remained in oxygenated ACSF for the duration of the experiment (20-30 $\mathrm{min})$. At the conclusion of each experiment, slices were placed in $4 \%$ paraformaldehyde for $\sim 2 \mathrm{hr}$, and subsequently washed three times in PBS, and remained in PBS overnight. The neurobiotin conjugate streptavidin Alexa 488 diluted 1:500 in PBS $+0.3 \%$ Triton X-100 was added overnight. Slices were washed three times in PBS to remove excess streptavidin Alexa 488 and viewed immediately under a confocal microscope. Because $\mathrm{Ca}^{2+}$ indicator dyes fix poorly by aldehydes, the bulk-loading procedure revealed cells that were labeled only by streptavidin Alexa 488.

Analysis of neuronal currents. Neuronal AMPA sEPSCs were analyzed in four to five bins that were sized equal to the duration of the evoked $\mathrm{Ca}^{2+}$ elevation in astrocyte cell bodies (see Results). The bins as they appear in the figures and text were named according to their placement relative to the UV light pulse administered to the astrocyte: "before," "during," "after," "second after," and "third after." The amplitudes and kinetics of the spontaneous currents were analyzed using the MiniAnalysis program (version 5.2.4; Synaptosoft Inc., Decatur, GA). Individual currents were detected over noise by setting a threshold for amplitude and area that resulted in minimal detection of false positives. This inevitably led to nondetection of very small amplitude currents, but this condition was preferred to making currents out of noise. Currents that were falsely detected were rejected manually, including those from electrical interference (with a zero time component) and when single sEPSCs were counted twice. sEPSC frequency was calculated by dividing the number of events in a bin by the bin duration (in seconds). We discovered substantial variability in the average amplitude and frequency of currents between cells. The average baseline amplitude in the 12 neurons included in the experimental condition was $13.1 \pm 4.5 \mathrm{pA}$ (mean $\pm \mathrm{SD}$; range, $8.5-21.3 \mathrm{pA}$ ). In individual cells, frequencies ranged from 0.071 to $0.815 \mathrm{~Hz}$, for an average of $0.282 \pm 0.237 \mathrm{~Hz}$. The substantial variability in baseline recordings between neurons suggested that significant changes in neuronal currents might be lost if analyzed as a single population. Data from individual neurons were therefore normalized by dividing the average baseline (before bin) data into the average data of each remaining bin. Thus, data were expressed as a percentage of average before bin amplitude or frequency. The Student's $t$ test was used to compare differences between normalized average before bin data to normalized data in each of the remaining bins. The number of neuron-astrocyte pairs, not the number of uncagings, was used in all statistical tests. All statistical tests were performed using PCLAMP 8.1 software.

OGB-1, calcium green 1-AM, nitrophenylethyl-caged inositol 1,4,5- $\mathrm{P}_{3}$ (caged $\left.\mathrm{IP}_{3}\right), \mathrm{N}$-(2-aminoethyl)biotinamide hydrobromide (neurobiotin), streptavidin Alexa Fluor 488 conjugate, pluronic acid, and Alexa 568 hydrazide dye were obtained from Molecular Probes (Eugene, OR). LY367385, MPEP, NBQX and trans ( \pm )-1-aminocyclopentane-trans1,3-dicarboxylic acid (tACPD) were purchased from Tocris Cookson (Ellisville, MO). FVB/N-TgN (GFAP-GFP) mice were obtained from The Jackson Laboratory and backcrossed one to five generations to C57BL/6J mice.

\section{Results \\ Identification of astrocytes and electrophysiological properties}

We made use of heterozygous GFAP-eGFP mice in some experiments to assist our identification of astrocytes (Zhuo et al., 1997). In these mice, the expression of enhanced green fluorescent protein is driven by the GFAP promoter. Therefore, GFAP ${ }^{+}$ cells appeared light green under the confocal microscope. Astrocytes in the stratum radiatum of acute mouse hippocampal slices were initially identified using DIC optics. In slices from GFAPeGFP mice, this identification was verified by their green fluorescence and then confirmed by their electrophysiological properties. $\mathrm{GFAP}^{+}$astrocytes exhibited a typical morphology (see Fig. $3 a$ ) and passive whole-cell currents. These cells had resting membrane potentials of $-85.1 \pm 0.5 \mathrm{mV}$ and very low membrane resistances $\left(R_{\mathrm{m}}=10.2 \pm 1.7 \mathrm{M} \Omega ; n=30\right.$ cells $)$.

\section{Uncaging $\mathrm{IP}_{3}$ produces an intracellular wave of calcium}

Before studying the effects of evoking increases in astrocyte $\mathrm{Ca}^{2+}$ on neuronal activity, it was first necessary to determine the effectiveness of our uncaging approach as well as characterize the evoked $\mathrm{Ca}^{2+}$ responses in astrocytes. We estimated the size of the UV light pulse and the velocity of the evoked $\mathrm{Ca}^{2+}$ wave in the same astrocyte. Astrocytes in the stratum radiatum of CA1 displaying prominent horizontal processes (Fig. 1a) were loaded with $200 \mu \mathrm{M}$ of the $\mathrm{Ca}^{2+}$ indicator dye OGB-1 plus $400 \mu \mathrm{M}$ caged $\mathrm{IP}_{3}$ via patch pipette. Uncaging $\mathrm{IP}_{3}$ was only possible after removal of the patch pipette. We believe that this is caused by dilution of free $\mathrm{IP}_{3}$ by the large reservoir of the pipette solution. $\mathrm{IP}_{3}$ was uncaged in the astrocyte soma by a short $(10 \mathrm{msec})$ pulse of UV light during a $10 \mathrm{sec}$ horizontal line scan (12.27 msec per line) over (1) the cell body, (2) the UV light spot, and (3) the large horizontal process (blue line in Fig. 1a). The resulting line scan image shows a $\sim 2.50 \mu \mathrm{m}$ region of the astrocyte soma in which the fluorescence increase over baseline fluorescence $\left(\Delta F / F_{0}\right)$ occurred simultaneously, providing an approximate diameter of the UV light pulse (Fig. $1 b$ ). In the remainder of the line scan image $\Delta F / F_{0}$ occurred in the astrocyte with an increasing time delay (Fig. $1 b$, slope of fluorescence increase), suggesting that a $\mathrm{Ca}^{2+}$ wave propagated outward from the uncaging spot. To better visualize $\Delta F / F_{0}$ produced by uncaging $\mathrm{IP}_{3}$, line scan images were fitted with a threshold function using ImageJ software (Bethesda, MD) (Fig. 1c). The rate of the $\mathrm{Ca}^{2+}$ wave was then estimated by measuring the time required for $\Delta F / F_{0}$ to travel a set distance down the large proximal process. The $\mathrm{Ca}^{2+}$ signal traveled $7.0 \mu \mathrm{m}$ in $286 \mathrm{msec}$, giving a rate of $24.6 \mu \mathrm{m} / \mathrm{sec}$ (Fig. 1d).

To make sure that the UV light pulse alone did not elevate astrocyte $\mathrm{Ca}^{2+}$, astrocytes were loaded with $\mathrm{Ca}^{2+}$ indicator dye only and subjected to pulses of UV light. These experiments were performed with the wavelength filters removed from the laser to visualize the precise timing during a confocal line scan that the pulse of UV light was applied (see Materials and Methods). Even when the laser was configured to deliver pulses of much higher intensity than those used to uncage $\mathrm{IP}_{3}, \mathrm{Ca}^{2+}$ increases were not observed in astrocytes (Fig. $1 e-g$ ).

Uncaging $\mathrm{IP}_{3}$ produced a $\mathrm{Ca}^{2+}$ increase over the point of uncaging after a brief ( $40 \mathrm{msec})$ delay. This delay was measured using a $2 \mathrm{sec}$ line scan centered over the UV light spot in the astrocyte soma (Fig. $2 a$ ). Uncaging $o$-nitrophenyl EGTA (caged $\mathrm{Ca}^{2+}$ ) produced a $\mathrm{Ca}^{2+}$ elevation in $<2.83 \mathrm{msec}$ (data not shown), indicating that the uncaging process contributed very little to the $40 \mathrm{msec}$ delay observed after $\mathrm{IP}_{3}$ uncaging. These observations suggest that the $40 \mathrm{msec}$ delay reflects the time required for $\mathrm{IP}_{3}$ to activate $\mathrm{IP}_{3}$ receptors and release $\mathrm{Ca}^{2+}$ from internal stores. The $\mathrm{Ca}^{2+}$ signal initiated in the cell body and then traveled as a wave into the astrocyte processes (Fig. $2 b$ ). As the $\mathrm{Ca}^{2+}$ wave traveled into astrocyte processes, the amplitude and duration of $\Delta F / F_{0}$ decreased, but small, brief fluorescence increases were evident even in the finest processes (Fig. 2b,c). Multiple $\mathrm{IP}_{3}$ uncaging responses were routine in the same astrocyte. The amplitude and duration of these remained consistent (Fig. 3). After a maximum of 15-20 uncagings, $\mathrm{Ca}^{2+}$ increases ceased without an increase in baseline fluorescence, suggesting that basal cytosolic $\mathrm{Ca}^{2+}$ levels remained low and that caged $\mathrm{IP}_{3}$ had been used up. The duration of the evoked $\mathrm{Ca}^{2+}$ responses varied from 7 to $24 \mathrm{sec}$ between cells (average, $16 \mathrm{sec}$ ). 

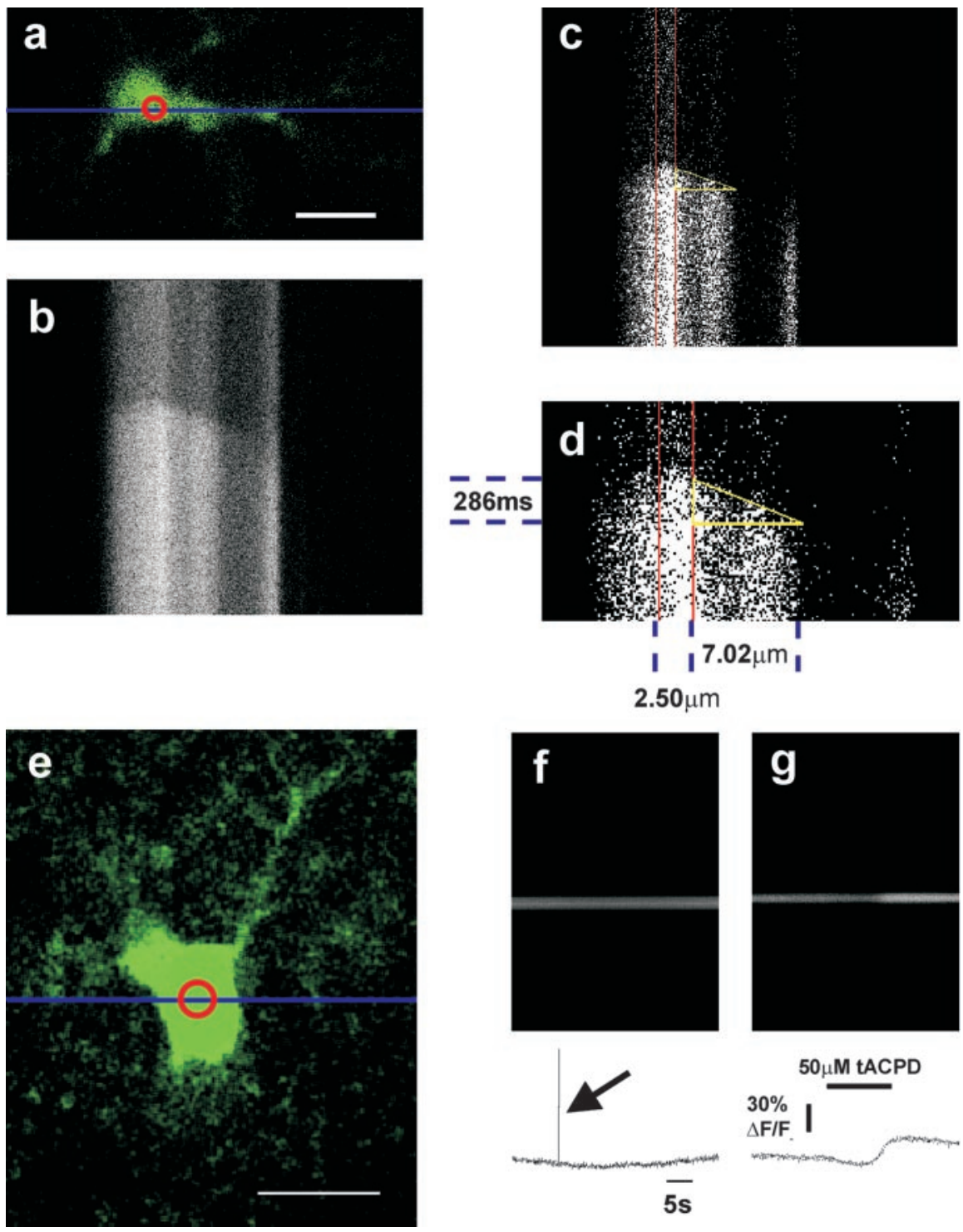
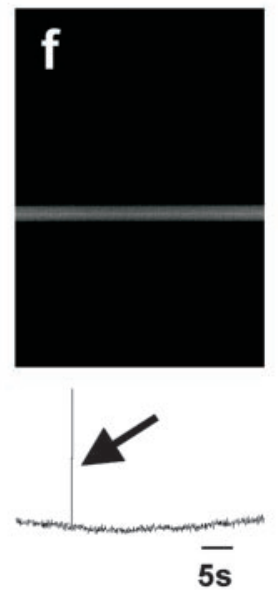

$\mathbf{S}$

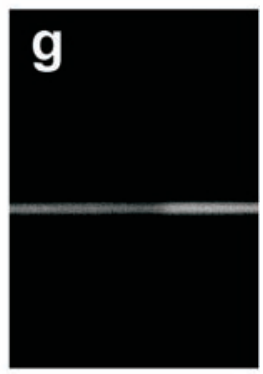

$50 \mu \mathrm{M}$ tACPD

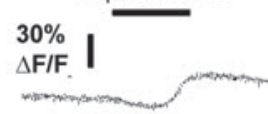

Figure 1. The diameter of the UV light pulse and the rate of the $\mathrm{Ca}^{2+}$ wave are estimated. $a$, Astrocytes with large processes oriented parallel to the line scan were patch clamped with pipettes containing $200 \mu \mathrm{M} \mathrm{Ca}{ }^{2+}$ indicator dye 0GB-1 and $400 \mu \mathrm{M}$ caged $I P_{3}$. The blue line is the line scan position. The red circle is the estimated diameter of the UV light pulse (see below). $b, I_{3}$ uncaged during a 10 sec line scan revealed a $\mathrm{Ca}^{2+}$ increase that did not occur simultaneously in all parts of the cell. The portion of the soma in which $\mathrm{Ca}^{2+}$ increased simultaneously had a diameter of $\sim 2.5 \mu \mathrm{m}$. This provided an estimate of the UV beam diameter. In the remaining parts of the cell, $\mathrm{Ca}^{2+}$ increased after a delay that was longer with distance from the uncaging point, indicating a $\mathrm{Ca}^{2+}$ wave. $c$, The line scan image in $b$ was fitted with a threshold function to see the $\mathrm{Ca}^{2+}$ increase in the astrocyte more easily. The red box represents the beam diameter estimate and the yellow lines represent distance, time, and slope. The estimate in this cell was restricted to the proximal process, as more distally the process dipped out of focus. $d$, A zoomed-in image of $c$ showing that the $\mathrm{Ca}^{2+}$ signal traveled $7.0 \mu \mathrm{m}$ in $286 \mathrm{msec}$, for an estimate of $24.6 \mu \mathrm{m} / \mathrm{sec}$. $e-g$, UV light alone did not produce $\mathrm{Ca}^{2+}$ elevations in astrocytes. $f, 40$ sec line scan showing no effect of a $10 \mathrm{msec}$ UV light pulse on fluorescence of an astrocyte patched with $0 G B-1$ only. The trace below the line scan indicates the relative change in fluorescence in the astrocyte soma over the duration of the scan. The $10 \mathrm{msec}$ light artifact (arrow) is produced when neutral density and UV wavelength filters are removed from the laser. This results in a beam of high intensity that indicates when the UV pulse was applied. $g$, To make sure that the astrocyte was capable of producing a $\mathrm{Ca}^{2+}$ increase, $50 \mu \mathrm{m}$ tACPD was added to the bathing solution. Scale bars, $10 \mu \mathrm{m}$.

\section{Comparison of evoked responses to intrinsic $\mathrm{Ca}^{2+}$}

\section{oscillations in astrocytes}

In addition to $\mathrm{Ca}^{2+}$ increases evoked by uncaging $\mathrm{IP}_{3}$, astrocytes exhibited spontaneous (intrinsic) $\mathrm{Ca}^{2+}$ oscillations. Although the mechanism of intrinsic $\mathrm{Ca}^{2+}$ oscillations remains unclear, like evoked responses, they are dependent on $\mathrm{Ca}^{2+}$ release from internal stores (Nett et al., 2002). Previous work has shown that intrinsic $\mathrm{Ca}^{2+}$ oscillations occur localized within microdomains of astrocyte processes, and that $\mathrm{Ca}^{2+}$ oscillations in one process are not in synchrony with $\mathrm{Ca}^{2+}$ oscillations in other processes (Nett et al., 2002). In the present study, the majority of intrinsic $\mathrm{Ca}^{2+}$ oscillations initiated in processes and a few of these traveled back into the astrocyte soma as a $\mathrm{Ca}^{2+}$ wave (Fig. 3b,c). Many intrinsic oscillations in astrocyte processes remained very local, because they were not seen to propagate into other regions of interest (Fig. $3 b$ ). In the event that an intrinsic $\mathrm{Ca}^{2+}$ oscillation initiated at or near the astrocyte soma, it was very similar in amplitude to $\mathrm{Ca}^{2+}$ responses evoked by uncaging $\mathrm{IP}_{3}$ (Fig. $3 b$ ). Because the intrinsic oscillations shared certain characteristics with the $\mathrm{IP}_{3}$ uncaging $\mathrm{Ca}^{2+}$ responses, neuronal AMPA sEPSCs were analyzed before and after intrinsic $\mathrm{Ca}^{2+}$ oscillations occurring in astrocyte somata. There was no significant change in the amplitude or frequency of neuronal AMPA sEPSCs recorded during intrinsic astrocyte $\mathrm{Ca}^{2+}$ oscillations (data not shown). Evoked $\mathrm{Ca}^{2+}$ elevations in astrocytes differed most from intrinsic oscillations in that they were always initiated in the cell body, and the $\mathrm{Ca}^{2+}$ signal spread from the UV light spot as a wave into most, if not all, visible astrocyte processes (Fig. $3 d$ ). Even in fine processes up to $35 \mu \mathrm{m}$ away, $\mathrm{Ca}^{2+}$ increased after $\mathrm{IP}_{3}$ uncaging in the astrocyte soma (Fig. $3 a, d$ ). Thus, uncaging $\mathrm{IP}_{3}$ in the astrocyte soma synchronized $\mathrm{Ca}^{2+}$ activity in astrocyte microdomains. This was considered to be a very important feature of $\mathrm{IP}_{3}$ uncaging responses, because a coordinated release of glutamate by astrocyte processes surrounding neuronal synapses might increase the probability of measuring an effect on whole-cell neuronal currents.

\section{Evoked astrocyte $\mathrm{Ca}^{2+}$ waves do not} propagate into neighboring astrocytes $\mathrm{Ca}^{2+}$ elevations in single astrocytes in vitro very often propagate as a wave into neighboring astrocytes, an activity that is mediated in part by mechanical coupling between astrocytes via gap junctions (Iwabuchi et al., 2002). It was important for us to determine whether uncaging $\mathrm{IP}_{3}$ in a single astrocyte evoked a $\mathrm{Ca}^{2+}$ wave that spread into adjacent astrocytes; were this the case we might expect an enhanced effect of uncaging $\mathrm{IP}_{3}$ in a single astrocyte on neuronal activity. To address this issue, astrocytes in hippocampal slices from mice aged 10-14 d were bulk-loaded with $\mathrm{Ca}^{2+}$ green 1-AM ester dye, and a single astrocyte in a field of cells was loaded with OGB-1, $400 \mu \mathrm{m}$ caged $\mathrm{IP}_{3}$, and $1 \%$ neurobiotin via patch pipette (Fig. $4 a$ ). Neurobiotin was included in the pipette solution to determine whether astrocytes filled with OGB-1 and caged $\mathrm{IP}_{3}$ were coupled via gap junctions to neighboring astrocytes. Although the 

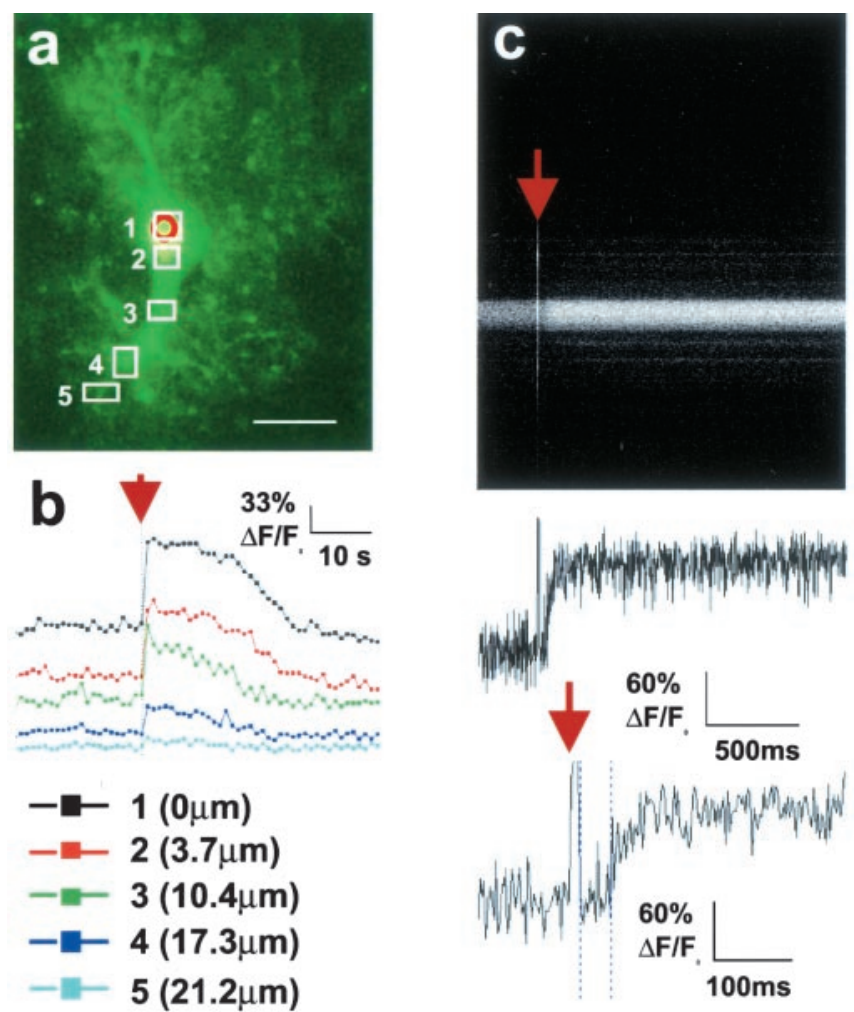

Figure 2. Uncaging $\mathbb{I P}_{3}$ in astrocytes produces a $\mathrm{Ca}^{2+}$ increase after a 40 msec delay, which then spreads into fine distal processes. $a$, An astrocyte patch clamped with a pipette containing caged $I_{3}$ and $0 G B-1$ showing the UV light spot (red circle) and five regions of interest where fluorescence was monitored. Scale bar, $10 \mu \mathrm{m}$. $b$, Change in fluorescence over baseline $\left(\Delta F / F_{0}\right)$ was brightest over the point of uncaging, but responses were still measured in the fine terminal processes up to $21 \mu \mathrm{m}$ away (trace 5). Note that $\mathrm{IP}_{3}$ was uncaged in a $2.5 \mu \mathrm{m}$ diameter region in the astrocyte soma, and the $\mathrm{Ca}^{2+}$ increases measured in other astrocyte compartments were caused by $\mathrm{Ca}^{2+}$ spreading as a wave into these regions. The $\mathrm{Ca}^{2+}$ wave is not clearly evident in $b$ because of the time scale required to show the size and shape of the entire $\mathrm{Ca}^{2+}$ signal. Multiple uncagings in the same cell produced $\mathrm{Ca}^{2+}$ elevations of nearly uniform duration, but a variable duration of 7-24 sec was observed between cells (average, $16 \mathrm{sec}$ ). c, A 2 sec line scan showing the UV light artifact (arrow), which was used to determine the delay to onset of the $\mathrm{Ca}^{2+}$ elevation after uncaging of $\mathrm{IP}_{3}$. The $40 \mathrm{msec}$ delay predominantly reflects the kinetics of the $\mathrm{IP}_{3}$ receptor, because uncaging 0 -nitrophenyl EGTA (caged $\mathrm{Ca}^{2+}$ ) results in $\mathrm{Ca}^{2+}$ elevations with no discernible delay ( $<2.83 \mathrm{msec}$ ) using a 2 sec line scan (data not shown).

patched cell was also bulk-loaded by $\mathrm{Ca}^{2+}$ green 1-AM dye, bulk loading tended to be very light and did not interfere with $\mathrm{Ca}^{2+}$ responses produced by $\mathrm{IP}_{3}$ uncaging (Fig. $4 c$ ). Furthermore, because astrocytes occupy distinct, nonoverlapping anatomical domains (Bushong et al., 2002), we were confident that we would not record false positive $\mathrm{Ca}^{2+}$ responses in cell bodies of neighboring bulk-loaded astrocytes on $\mathrm{IP}_{3}$ uncaging in the single patch-clamped astrocyte. Uncaging $\mathrm{IP}_{3}$ resulted in robust $\mathrm{Ca}^{2+}$ increases in the single patch-clamped astrocyte, but these never propagated to adjacent cells ( $n=8$ cells in eight slices) (Fig. $4 c$ ), despite extensive coupling of the patched cell to astrocytes throughout the hippocampus (Fig. 4b). To ensure that neighboring cells were capable of producing a $\mathrm{Ca}^{2+}$ response, $50 \mu \mathrm{M}$ tACPD was added to the extracellular solution. Neighboring cells that were clearly able to produce a $\mathrm{Ca}^{2+}$ increase by tACPD did not increase $\mathrm{Ca}^{2+}$ after $\mathrm{IP}_{3}$ uncaging in the single patch-clamped cell. Because tACPD produced $\mathrm{Ca}^{2+}$ responses of much longer duration than $\mathrm{IP}_{3}$ uncaging responses, a concern was that the comparatively brief uncaging responses were not potent enough to elevate $\mathrm{Ca}^{2+}$ in neighboring cells. However, even when trains of UV pulses were given to the pipette-loaded cell to lengthen the evoked response, $\mathrm{Ca}^{2+}$ in adjacent cells remained at baseline levels (Fig. 4c). These data suggest that although $\mathrm{IP}_{3}$ uncaging results in a robust intracellular $\mathrm{Ca}^{2+}$ wave, this wave does not propagate into adjacent astrocytes in situ.

\section{Uncaging $\mathrm{IP}_{3}$ in astrocytes increases the frequency of neuronal AMPA sEPSCs}

We next investigated whether uncaging $\mathrm{IP}_{3}$ in astrocytes affected neuronal activity by monitoring AMPA sEPSCs in adjacent CA1 pyramidal neurons. AMPA sEPSCs were isolated as explained in Materials and Methods. Astrocytes in the stratum radiatum among proximal apical dendrites of CA1 pyramidal cells were patch-clamped with a solution containing OGB-1 and caged $\mathrm{IP}_{3}$. A CA1 pyramidal neuron extending its apical dendrite in the same optical plane as the astrocyte was then patch-clamped with a pipette containing Alexa Fluor 568 hydrazide dye solution. This enabled us to visualize the proximity of neuronal and astrocyte compartments using a single optical section (Fig. $5 a$; see also Figs. $6 a, 7 a)$. Spontaneous whole-cell AMPA currents were then recorded while uncaging $\mathrm{IP}_{3}$ in the astrocyte. Because there are some data to suggest that $\mathrm{Mg}^{2+}$ block of NMDA receptors is incomplete at resting membrane potentials (Kovalchuk et al., 2000 ), it is possible that the currents evoked by uncaging $\mathrm{IP}_{3}$ in adjacent astrocytes were mediated by NMDA, not AMPA, receptors. To check this, NMDA receptor currents were isolated in a separate experiment using $\mathrm{Mg}^{2+}$-free ACSF plus $10 \mu \mathrm{M}$ NBQX. NMDA-receptor-mediated currents displayed significantly slower $10-90 \%$ rise time and decay time constant compared with AMPAR-mediated currents (10-90\% rise times: $5.0 \pm 0.3 \mathrm{msec}$ NMDA, $3.9 \pm 0.2 \mathrm{msec}$ AMPA, $p=0.009$; decay time constant: $27.7 \pm 2.2 \mathrm{msec}$ NMDA, $10.7 \pm 1.0 \mathrm{msec}$ AMPA, $p<0.001)$. All currents recorded, even those that occurred after uncaging $\mathrm{IP}_{3}$ in astrocytes, displayed kinetics typical of AMPARs. AMPA currents were analyzed in bin sizes based solely on the duration of the increase in astrocyte $\mathrm{Ca}^{2+}$ after uncaging. These were labeled before (before uncaging $\mathrm{IP}_{3}$ in the astrocyte), during (during the evoked astrocyte $\mathrm{Ca}^{2+}$ increase), after (the first bin after astrocyte $\mathrm{Ca}^{2+}$ returned to baseline), and second after (the second bin after astrocyte $\mathrm{Ca}^{2+}$ returned to baseline) (Fig. 5b). An average of six evoked $\mathrm{Ca}^{2+}$ elevations per neuron-astrocyte pair was analyzed. In 48 of 71 uncaging events $(68 \%)$, evoked $\mathrm{Ca}^{2+}$ elevations in astrocytes were accompanied by an increased frequency of AMPA sEPSCs that peaked shortly after astrocyte $\mathrm{Ca}^{2+}$ returned to baseline (Fig. 5b). AMPA sEPSC frequency, normalized as a percentage of average before bin frequency, was significantly increased in bins during, after, and second after compared with the before bin ( $p<0.05$ by Student's $t$ test; $n=12$ neuron-astrocyte pairs) (Fig. $5 c)$. These results suggest that evoking $\mathrm{Ca}^{2+}$ waves in single astrocytes triggers release of neuroactive molecules to modulate the activity of adjacent CA1 pyramidal neurons. Because the frequency of the AMPA currents remained elevated in the second after bin, a third after bin was analyzed. The frequency of neuronal currents was not significantly different in the third after bin compared with before uncaging $(p=0.11)$ (Fig. $5 c$ ). The normalized amplitude of AMPA currents, although increased, was not statistically significant in any of the bins compared with the before bin (during, $p=0.11$; after, $p=0.06$; second after, $p=$ 0.08 ). Although not statistically significant, the $15 \%$ increase in AMPA current amplitudes is considerable given that $\mathrm{IP}_{3}$ is uncaged in a single astrocyte, and many astrocytes associate with an individual CA1 pyramidal cell. The kinetics of the AMPA currents were unaffected by uncaging $\mathrm{IP}_{3}$ in astrocytes $(10-90 \%$ rise 

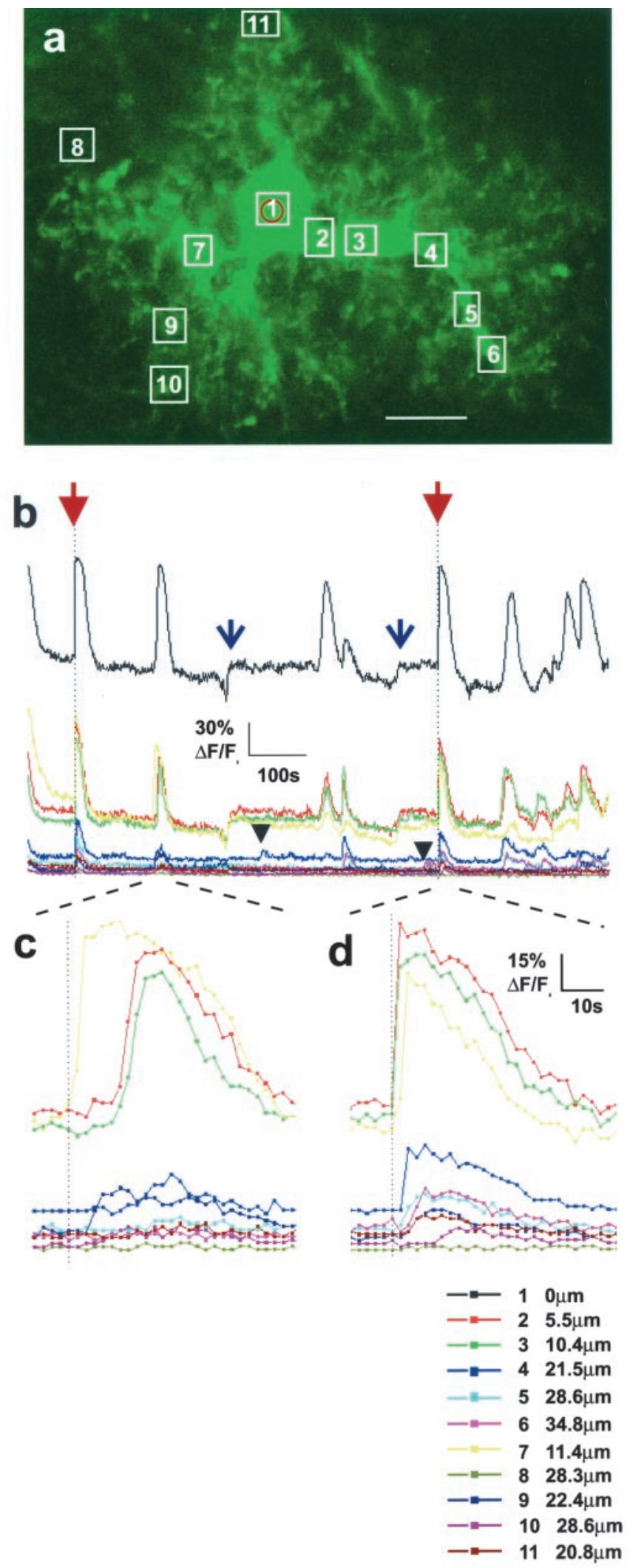

Figure 3. $\mathrm{Ca}^{2+}$ responses to uncaging $\mathrm{IP}_{3}$ resemble intrinsic astrocyte $\mathrm{Ca}^{2+}$ oscillations. $a$, A large astrocyte loaded with caged $\mathrm{IP}_{3}$ and $0 \mathrm{~GB}-1$ by diffusion via the patch pipette. $\mathrm{IP}_{3}$ was uncaged in the zone marked by the red circle and regions of interest in which $\mathrm{Ca}^{2+}$ was monitored are numbered 1-11. Scale bar, $10 \mu \mathrm{m} . b, \mathrm{~A} 16 \mathrm{~min} \mathrm{Ca}^{2+}$ measurement including all regions of interest shows two individual $\mathrm{Ca}^{2+}$ increases produced by uncaging $\mathrm{IP}_{3}$ (red arrows) together with intrinsic $\mathrm{Ca}^{2+}$ oscillations. Blue arrows indicate baseline shifts in fluorescence caused by refocusing the cell. Note that uncaging responses are similar in size to intrinsic $\mathrm{Ca}^{2+}$ times: $p=0.91$, before vs during; $p=0.70$, before vs after; $p=$ 0.65 , before vs second after; decay time constants: $p=0.56$, before vs during; $p=0.32$, before vs after; $p=0.34$, before vs second after), suggesting that if glutamate was released by astrocytes during evoked $\mathrm{Ca}^{2+}$ waves, it did not activate postsynaptic neuronal AMPARs directly.

To ensure that the UV laser pulse alone was not sufficient to release neuroactive molecules from astrocytes, astrocytes patched-clamped and filled with $\mathrm{Ca}^{2+}$ dye only were given pulses of UV light while recording neuronal AMPA sEPSCs (Fig. 6). Because the laser pulse alone did not increase astrocyte $\mathrm{Ca}^{2+}$ (Fig 2 ), bin lengths were determined by taking the average length of the 71 evoked $\mathrm{Ca}^{2+}$ responses from the 12 cells that were patched with caged $\mathrm{IP}_{3}$. The average length of the evoked astrocyte $\mathrm{Ca}^{2+}$ responses was $16 \mathrm{sec}$. The frequency and amplitude of neuronal AMPA currents remained at baseline in all analyzed bins (before vs during, $p=0.94$; before vs after, $p=0.62$; before vs second after, $p=0.45 ; n=9$ neuron-astrocyte pairs). Sample data from one uncaging in a single neuron-astrocyte pair is shown in Figure $6 b$. These results indicate that the release of signaling molecules from astrocytes to affect AMPA sEPSCs in adjacent CA1 pyramidal neurons requires elevations in astrocyte $\mathrm{Ca}^{2+}$.

\section{Increased frequency of neuronal AMPA sEPSCs requires group I mGluRs}

The lack of an effect of uncaging $\mathrm{IP}_{3}$ in astrocytes on the kinetics of neuronal AMPA sEPSCs suggested that astrocytes were modulating the frequency of AMPA currents without directly activating AMPA receptors. Studies have shown that presynaptic group I mGluRs facilitate the release of glutamate from synaptic terminals (Herrero et al., 1998; Rodriguez-Moreno et al., 1998; Schwartz and Alford, 2000; Thomas et al., 2001) and transiently increase the frequency of miniature EPSCs (mEPSCs) recorded in CA1 pyramidal cells (Rodriguez-Moreno et al., 1998; Fitzjohn et al., 2001b). We attempted to block the increase in AMPA sEPSC frequency recorded in CA1 pyramidal neurons using the selective group I metabotropic receptor antagonists LY367385 $(10 \mu \mathrm{M})$ and MPEP $(10 \mu \mathrm{M})$. LY367385 is a potent and selective antagonist of $\mathrm{mGluR}_{1 \mathrm{a}}$, with negligible action on group II and group III receptors (Clark et al., 1997), and MPEP is a potent and highly selective noncompetitive antagonist at the $\mathrm{mGluR}_{5}$ receptor subtype (Gasparini et al., 1999). In these experiments, conditions were identical to those in the experimental condition, in which evoked astrocyte $\mathrm{Ca}^{2+}$ corresponded to an increased frequency of neuronal AMPA sEPSCs, except that the group I mGluR antagonists were washed into the slice bathing solution 2-3 min before uncaging $\mathrm{IP}_{3}$. It is important to note that the group I mGluR antagonists by themselves had little effect on the amplitude or frequency of spontaneous neuronal currents (amplitudes: before, $11.32 \mathrm{pA}$; after, $10.64 \mathrm{pA} ; p=0.52$; frequency: before, $0.379 \mathrm{~Hz}$; after, $0.308 \mathrm{~Hz} ; p=0.49 ; n=9$ neurons). In the presence of the group I mGluR blockers, uncaging $\mathrm{IP}_{3}$ in astro-

oscillations occurring in the astrocyte soma. Most intrinsic oscillations originate in processes; some of these travel back to the cell body (as in c), but many never reach the cell body (small black arrows). Two regions of the $\mathrm{Ca}^{2+}$ measurement denoted by the dotted lines are expanded to better resolve $\mathrm{Ca}^{2+}$ elevations in small astrocyte compartments in $c$, an intrinsic $\mathrm{Ca}^{2+}$ oscillation, and $d$, an $\mathbb{P P}_{3}$ uncaging $\mathrm{Ca}^{2+}$ response. $c$, A large intrinsic $\mathrm{Ca}^{2+}$ increase originating in region 7 traveled back to the cell body and spread to a limited number of other regions. Note the asynchrony in the timing that the wave reached other parts of the cell. $d$, $\mathrm{Ca}^{2+}$ responses evoked by uncaging $\mathbb{P}_{3}$ reliably propagated to all regions, synchronizing activity in the cell. In both $c$ and $d$, the response in region 1 was omitted to see more clearly the small responses in more distal regions. 

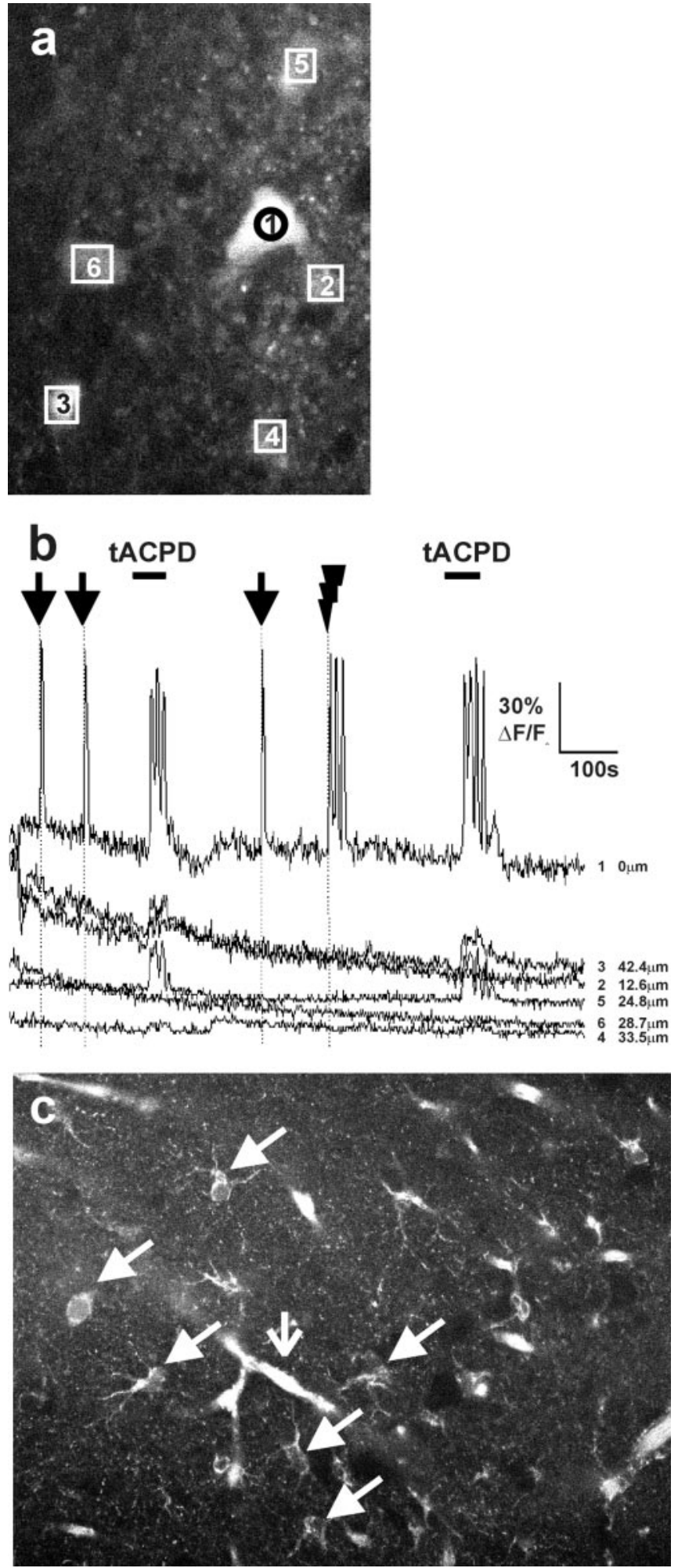

Figure 4. Uncaging $\mathrm{IP}_{3}$ in astrocytes produces an intracellular $\mathrm{Ca}^{2+}$ wave that does not propagate into neighboring cells. $a$, In a field of astrocytes bulk-loaded with $\mathrm{Ca}^{2+}$ green 1-AM ester dye, a single astrocyte marked by the UV light spot (cell 1) was patch clamped with pipettes containing $\mathrm{Ca}^{2+}$ dye $0 \mathrm{~GB}-1$, caged $\mathrm{IP}_{3}$, and $1 \%$ neurobiotin. Neurobiotin was included in the intracellular solution to show that gap junction coupling was not inhibited by any components of the intracellular solution used in the experiments. $b$, Cells 3 and 6 adjacent to the patched cell 1 responded to a perfusion of $50 \mu \mathrm{M} \mathrm{ACPD}$ with a $\mathrm{Ca}^{2+}$ elevation but did not increase $\mathrm{Ca}^{2+}$ after the robust $\mathbb{P}_{3}$ uncaging responses produced in cell 1 (arrows). Even a prolonged $\mathrm{Ca}^{2+}$ increase in cell 1 produced by a train of UV light pulses (10 pulses at $0.3 \mathrm{~Hz}$, lightning bolt) did not produce any $\mathrm{Ca}^{2+}$ increase in cells 3 and 6 . c, The astrocyte patched in $a$ cytes did not significantly increase the frequency of spontaneous whole-cell AMPA currents (before vs during, $p=0.41$; before vs after, $p=0.99$; before vs second after, $p=0.47 ; n=9$ neuronastrocyte pairs). Sample data from a single uncaging event in a neuron-astrocyte pair is shown in Figure $7 b$. These data suggest the following sequence of events: (1) Astrocytes release glutamate in response to evoked intracellular $\mathrm{Ca}^{2+}$ waves. (2) Glutamate released by astrocytes is sensed by neuronal presynaptic group I mGluRs. (3) Group I mGluR activation facilitates the spontaneous release of glutamate from neuronal presynaptic boutons, presumably via increases in presynaptic $\mathrm{Ca}^{2+}$. (4) The increased probability of spontaneous glutamate release is detected postsynaptically as an increased frequency of AMPA sEPSCs.

\section{Discussion}

Uncaging $\mathrm{IP}_{3}$ in astrocytes evoked an intracellular $\mathrm{Ca}^{2+}$ wave that correlated with an increased frequency of spontaneous AMPA currents in adjacent CA1 pyramidal neurons. The increased frequency of neuronal AMPA sEPSCs initiated during the rising phase of the astrocyte $\mathrm{Ca}^{2+}$ increase remained elevated for $48 \mathrm{sec}$, on average, and was repeatable within individual neuronastrocyte pairs. The effect on neuronal AMPA sEPSCs was not observed during perfusion of the group I mGluR antagonists LY367385 and MPEP. These results suggest that uncaging $\mathrm{IP}_{3}$ in astrocytes evoked glutamate release from astrocyte compartments adjacent to neuronal synapses, activating group I mGluRs to increase spontaneous glutamate release from presynaptic terminals.

Glutamate release by astrocytes has been induced by $\mathrm{Ca}^{2+}$. independent and $\mathrm{Ca}^{2+}$-dependent processes. $\mathrm{Ca}^{2+}$-independent mechanisms include: (1) reverse operation of glutamate transporters (for review, see Anderson and Swanson, 2000), (2) an anion channel-dependent pathway induced by swelling (Kimelberg et al., 1990), (3) release through connexin hemichannels (Ye et al., 2003), and (4) P2X $\mathrm{X}_{7}$-receptor-mediated release (Duan et al., 2003). The route by which glutamate is released by astrocytes in response to intracellular $\mathrm{Ca}^{2+}$ elevations is not yet firmly established, but evidence suggests a vesicular-dependent process (Parpura et al., 1995; Araque et al., 2000). Given that elevations in astrocyte $\mathrm{Ca}^{2+}$ are required to measure an increased frequency of neuronal AMPA sEPSCs in the present study, our model suggests a vesicular-dependent process for astrocyte glutamate release.

Calcium elevations evoked in astrocytes by uncaging $\mathrm{IP}_{3}$ were very similar in size and duration to the intrinsic $\mathrm{Ca}^{2+}$ oscillations observed in the astrocyte soma (Fig. 3). Intrinsic astrocyte $\mathrm{Ca}^{2+}$ oscillations occur in the absence of external stimulation. They occur independent of neuronal activity (Nett et al., 2002), require release of $\mathrm{Ca}^{2+}$ from internal stores (Nett et al., 2002), do not propagate into neighboring astrocytes (Nett et al., 2002), and may release glutamate to modulate the activity of adjacent neurons (Parri et al., 2001). Collectively, these results suggest that $\mathrm{Ca}^{2+}$ increases evoked by uncaging $\mathrm{IP}_{3}$ in astrocytes closely resemble intrinsic astrocyte $\mathrm{Ca}^{2+}$ oscillations. Because of this, we attempted to correlate intrinsic astrocyte $\mathrm{Ca}^{2+}$ oscillations to neuronal AMPA sEPSCs. We did not observe a significant effect on neuronal AMPA sEPSCs during intrinsic astrocyte $\mathrm{Ca}^{2+} \mathrm{ac}^{-}$

was extensively coupled to other astrocytes in the slice. Astrocytes (angled arrows) were clearly evident by the perinuclear labeling by streptavidin Alexa 488; a vertical arrow points to a blood vessel. The original patched cell could not be identified in part because of the vast number of coupled astrocytes, but also because $\mathrm{Ca}^{2+}$ indicator dyes fix poorly by aldehydes. These results were reproduced in eight different slices; never did a $\mathrm{Ca}^{2+}$ increase evoked by $\mathrm{IP}_{3}$ uncaging propagate to an adjacent cell. 

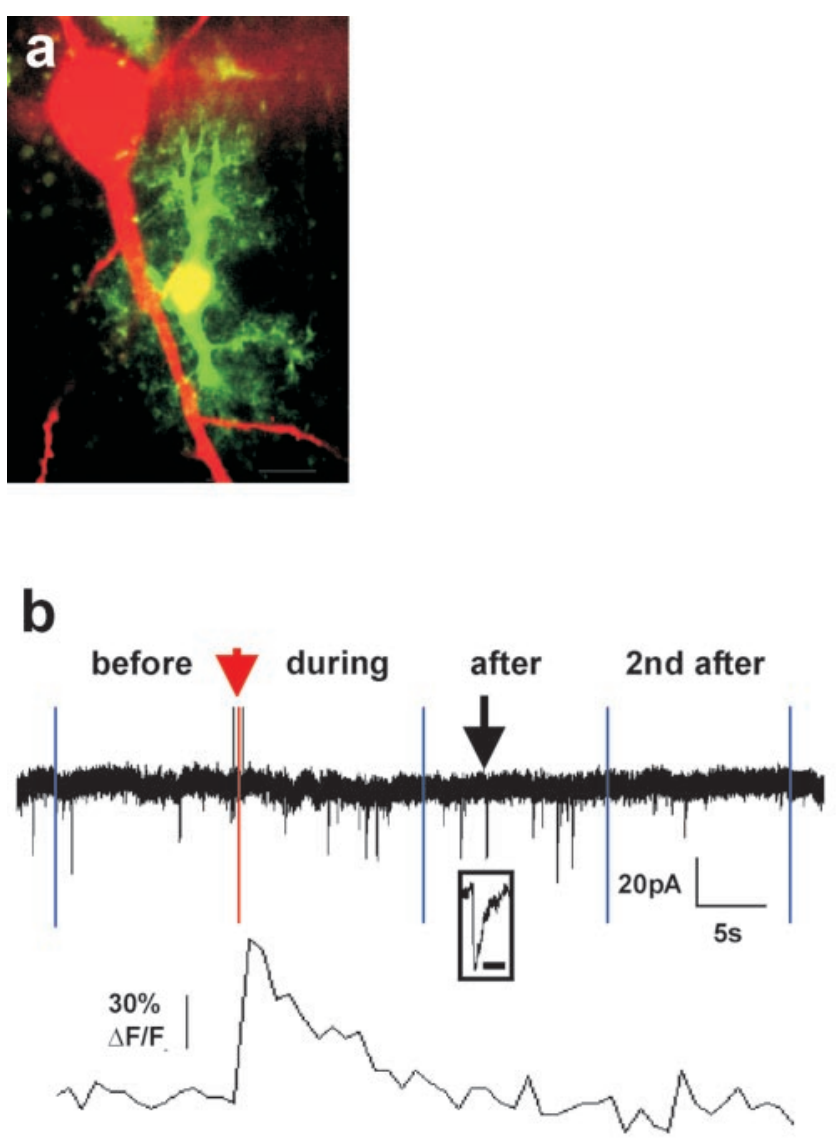

C Normalized Frequency

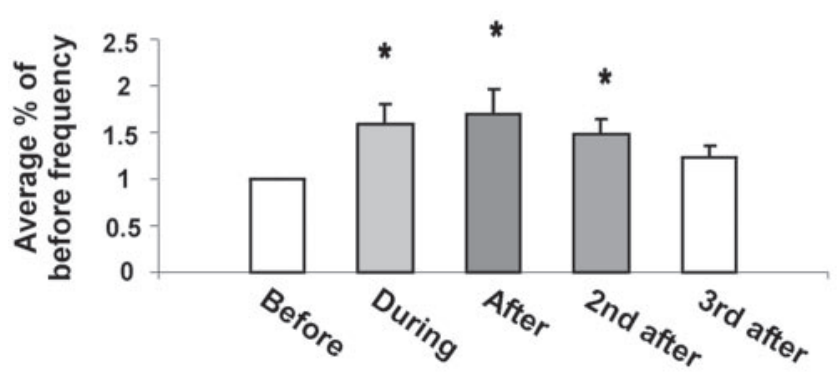

Figure 5. Evoked $\mathrm{Ca}^{2+}$ increases by uncaging $\mathbb{P}_{3}$ in astrocytes increase the frequency of AMPA receptor currents. $a$, Confocal image illustrating the morphological and spatial relationship between the neuron (red) and astrocyte (green) in the stratum radiatum of CA1. The astrocyte was patch clamped with pipettes containing 0 GB-1 and caged $\mathbb{P}_{3}$. The neuronal solution contained Alexa 568 hydrazide dye. This single optical section $(\sim 1.42 \mu \mathrm{m}$ thick) illustrates the proximity of the astrocyte to the pyramidal cell body as well as the size of the astrocyte and its processes relative to the neuron and its proximal apical dendrite. Scale bar, 10 $\mu \mathrm{m} . b$, Data from an individual neuron-astrocyte pair that best represents the overall average data. The top panel shows neuronal AMPA sEPSCs in four bins (before, during, after, and second after), and the bottom panel shows astrocyte calcium. The bin length was set equal to the duration of the $\mathrm{Ca}^{2+}$ elevation in the astrocyte. The red bar indicates the moment that the UV light pulse was applied. A single AMPA sEPSC is expanded to better show its time course (black arrowhead; scale bar, $20 \mathrm{msec})$. In this example, the frequencies for bins before, during, after, and second after were $0.308,0.538,0.769$, and $0.308 \mathrm{~Hz}$, respectively. c, Neuronal AMPA sEPSC frequency, normalized as a percentage of before bin frequency, was significantly increased in bins during, after, and second after relative to the before bin frequency ( $p<0.05$; Student's $t$ test $;=12$ cell pairs). A third after window was added because the frequency was significantly elevated in the second after window. The third after window frequency was not significantly different from the before window frequency ( $p=0.11$ ).
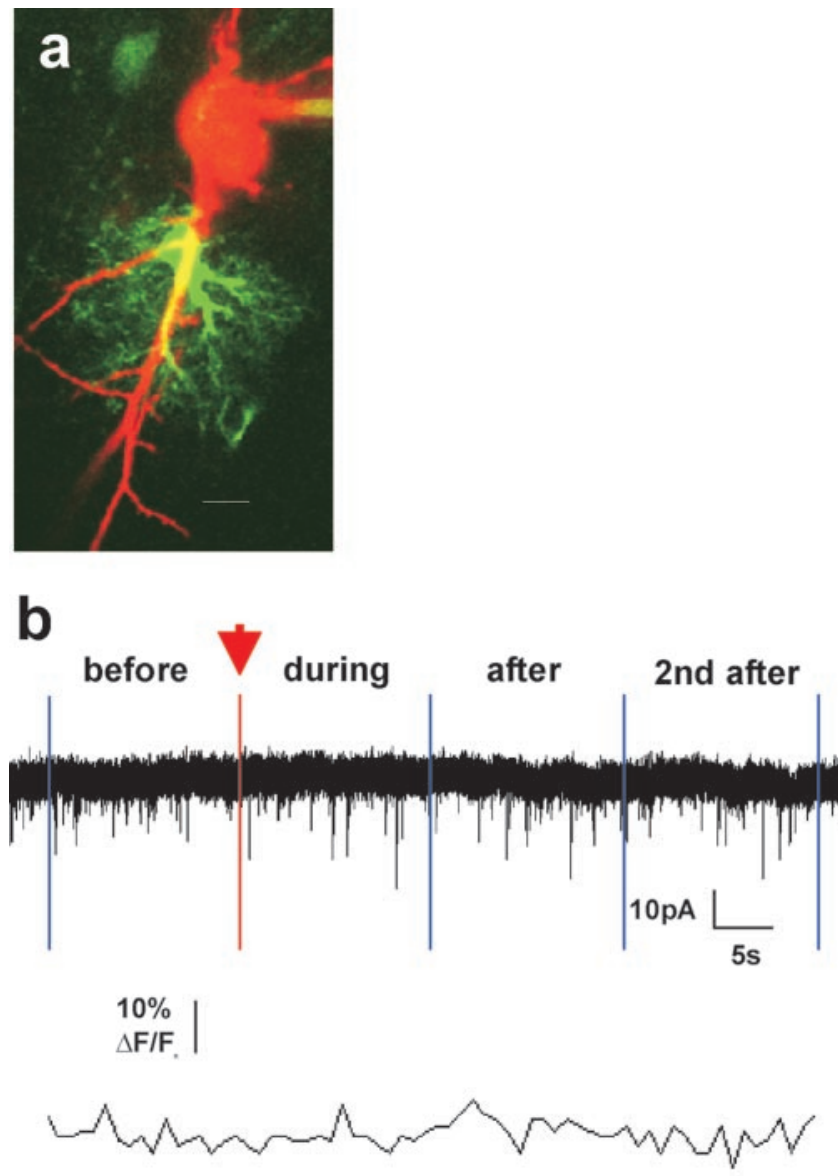

Figure 6. UV light pulses alone do not alter AMPA sEPSCs recorded in adjacent neurons. $a, A$ single optical section of a neuron-astrocyte pair in the control condition in which astrocytes were patched with OGB-1 $\mathrm{Ca}^{2+}$ indicator dye only. Scale bar, $10 \mu \mathrm{m} . b$, A UV light pulse equal in duration and intensity to those used in experimental conditions did not elevate astrocyte $\mathrm{Ca}^{2+}$ and did not change the frequency of neuronal AMPA sEPSCS $(1.688,1.500,1.500$, and $1.563 \mathrm{~Hz}$ for the four bins). All bins in control conditions are 16 sec long, the average duration of evoked $\mathrm{Ca}^{2+}$ increases in astrocytes patched with caged $\mathrm{IP}_{3}$.

tivity. It is possible that synchronized $\mathrm{Ca}^{2+}$ responses within (or among) astrocytes are required to measure an increased frequency of sEPSCs in CA1 pyramidal neurons (Pasti et al., 1997, Parri et al., 2001). Intrinsic astrocyte $\mathrm{Ca}^{2+}$ oscillations are not synchronized. They occur independently in separate astrocyte compartments, often initiate in processes and not in cell soma, and do not diffuse far from their point of origin (Nett et al., 2002). Furthermore, a single CA1 pyramidal cell apical dendrite is associated with many astrocytes, all exhibiting asynchronous intrinsic $\mathrm{Ca}^{2+}$ oscillations. Thus, focal detection of $\mathrm{Ca}^{2+}$ activity in astrocyte microdomains and in associated single dendritic spines may be necessary to record correlated intrinsic neuron-astrocyte activity. The significant effect observed on whole-cell neuronal currents in the present study is likely caused by the synchronized release of glutamate from astrocyte processes located proximal to the neuronal soma (see Figs. 5a, $6 a, 7 a$ for morphological proximity).

We did not differentiate between synaptic currents mediated by action potentials versus those mediated by quantal vesicular release. There is no obvious mechanism by which uncaging $\mathrm{IP}_{3}$ in a single astrocyte in the stratum radiatum of CA1 could depolarize Schaffer collateral axons to cause them to fire action poten- 


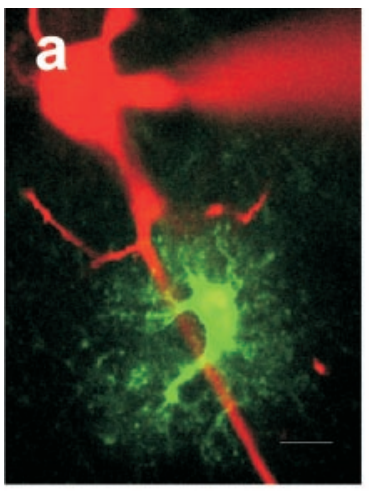

b

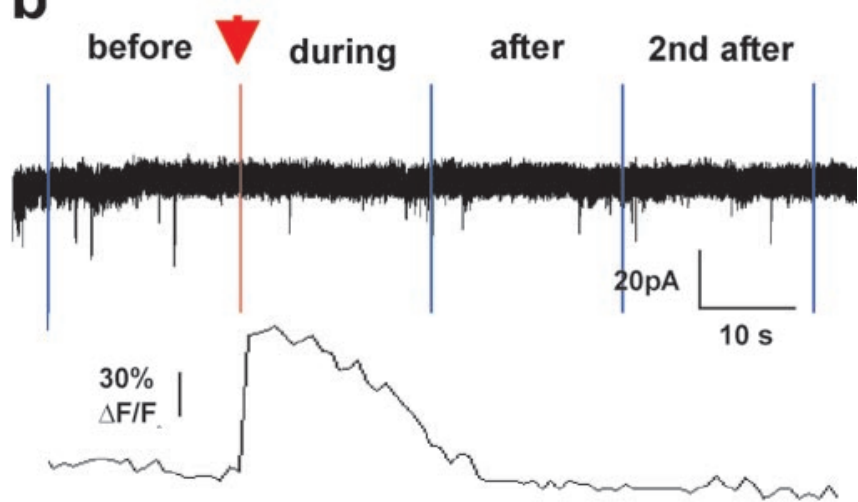

Figure 7. Increased frequency of neuronal AMPA sEPSCs is dependent on activation of group I metabotropic glutamate receptors. $a$, One of nine neuron-astrocyte pairs in which $\mathbb{I P}_{3}$ was uncaged in the astrocyte while recording AMPA sEPSCs in the neuron during perfusion of the group I mGluR antagonists LY367385 and MPEP (each $10 \mu \mathrm{M}$ ). This single optical section is $\leq 1.42 \mu \mathrm{m}$ thick. Scale bar, $10 \mu \mathrm{m} . b$, Despite strong evoked $\mathrm{Ca}^{2+}$ responses in astrocytes, the frequency and amplitude of neuronal AMPA currents remained at baseline when $\mathrm{mGlu}_{1 \mathrm{a}}$ and mGluR $_{5}$ receptors were blocked by LY367385 and MPEP, respectively. The top panel shows neuronal AMPA sEPSCs in the four bins (before, during, after, and second after), and the bottom panel shows astrocyte calcium. Perfusion of the group I mGluR antagonists alone did not change the baseline frequency or amplitude of AMPA sEPSCs (data not shown).

tials. However, because the probability of vesicular release in response to single action potentials at CA1 synapses is less than one (Hanse and Gustafsson, 2001; Oertner et al., 2002), it is possible that astrocytes increase the probability of vesicular release during spontaneous action potentials. Vesicular release is very tightly regulated by changes in presynaptic $\mathrm{Ca}^{2+}$ concentration (Schneggenburger and Neher, 2000). Therefore, astrocytemediated increases in presynaptic $\mathrm{Ca}^{2+}$ from internal stores by activation of group I mGluRs may work in concert with voltagegated $\mathrm{Ca}^{2+}$ channels to increase release probability. Calcium release from internal stores contributes to action-potentialmediated bouton transients and to paired-pulse facilitation of EPSPs (Emptage et al., 2001). In the absence of voltage-gated $\mathrm{Ca}^{2+}$ channel activation by incoming action potentials, the release of $\mathrm{Ca}^{2+}$ from bouton stores may not be sufficient to trigger vesicular release. The remaining possibility is that astrocytes affect the release probability of single quanta of transmitter. Spontaneous $\mathrm{Ca}^{2+}$ rises in CA3 neuronal synaptic boutons drive the quantal release of neurotransmitter (Emptage et al., 2001). Activation of group I mGluRs stimulates $\mathrm{Ca}^{2+}$ release from internal stores and therefore may increase spontaneous transmitter re- lease and the frequency of mEPSCs. Experiments that include TTX in the bathing solution will clarify whether the increase in frequency of AMPA sEPSCs is caused by increased miniature synaptic events or is dependent on spontaneous neuronal action potentials.

A key factor shaping the kinetics of ionotropic GluR (iGluR) currents is glutamate diffusion (for review, see Conti and Weinberg, 1999; Kullmann, 1999). Glutamate crossing the narrow gap of the synaptic cleft has limited diffusion constraints and therefore produces currents of rapid kinetics. To directly activate AMPA receptors, glutamate released by astrocytes would have to diffuse a greater distance through a larger volume of extrasynaptic solution. Therefore, it is predicted that glutamate released by astrocytes would produce very slow AMPA receptor currents (Conti and Weinberg, 1999). In the present study, we did not observe an effect of astrocyte $\mathrm{Ca}^{2+}$ elevations on neuronal AMPA current kinetics. This finding argues that glutamate released by astrocytes in situ does not directly activate postsynaptic AMPA receptors. Glutamate released by astrocytes may be limited to the activation of receptors localized outside synaptic specializations, in regions closer to astrocyte release sites. Our data suggest that glutamate released by astrocytes in situ activates extrasynaptic group I mGluRs to modulate the activity of neuronal AMPA currents.

Conflicting data have been published with regard to the function of mGluRs as facilitatory or inhibitory to the release of glutamate. Group I mGluRs are coupled to synthesis of $\mathrm{IP}_{3}$ and release of $\mathrm{Ca}^{2+}$ from bouton internal stores, providing a direct link between mGluR activation and vesicular release of transmitter. Facilitation of glutamate release by group I mGluRs has been shown in lamprey brainstem vestibulospinal-reticulospinal synapses (Schwartz and Alford, 2000), rat cerebrocortical synaptosomes (Herrero et al., 1998), rat forebrain slices (Thomas et al., 2001), and in the rat corpus striatum in vivo (Thomas et al., 2001). However, the evoked release of glutamate is inhibited after the application of the specific group I mGluR agonist $(R S)$-3,5dihydroxyphenylglycine (DHPG) (Gereau and Conn, 1995; Anwyl, 1999; Cartmell and Schoepp, 2000), and the effect of DHPG on spontaneous glutamate release is unclear (Gereau and Conn, 1995; Rodriguez-Moreno et al., 1998; Fitzjohn et al., 2001b). The discrepancies in these data may be explained by a functional switch from facilitation to inhibition in the control of glutamate release by group I mGluRs that is dependent on the duration of mGluR activation (Herrero et al., 1998; Rodriguez-Moreno et al., 1998). DHPG transiently increases the frequency of mEPSCs in CA1 pyramidal cells (within 2 min), whereas prolonged DHPG exposure $(>5 \mathrm{~min}$ ) results in desensitization of group I mGluRs and decreased frequency of mEPSCs (Rodriguez-Moreno et al., 1998). Inhibition of evoked glutamate release appears to occur by blockade of voltage-gated calcium channels, whereas the facilitation of spontaneous glutamate release may occur via release of $\mathrm{Ca}^{2+}$ from bouton stores and/or by phosphorylation of both $\mathrm{K}^{+}$ and $\mathrm{Ca}^{2+}$ channels by PKC (Herrero et al., 1998). In the present study, after uncaging $\mathrm{IP}_{3}$ in astrocytes the increased frequency of neuronal AMPA sEPSCs lasted $48 \mathrm{sec}$ on average, suggesting a transient, facilitatory action of glutamate released by astrocytes on mGluRs.

Increased frequency of AMPA sEPSCs after astrocyte glutamate release and activation of neuronal group I mGluRs may contribute to long-term synaptic plasticity. Previous work has shown that spontaneous vesicular glutamate release exerts a trophic effect on spines by acting at AMPARs (McKinney et al., 1999), and that group I mGluRs are involved in both LTD (An- 
wyl, 1999; Bortolotto et al., 1999; Fitzjohn et al., 2001b) and LTP (Manahan-Vaughan and Reymann, 1997; Cohen et al., 1998; Bortolotto et al., 1999; Raymond et al., 2000). The strength and timing of group I mGluR activation may code for the direction of long-term synaptic changes. For example, long-term exposure of group I mGluRs to DHPG induces a form of LTD that may occur by the internalization of synaptic AMPARs (Bortolotto et al., 1999; Fitzjohn et al., 2001b). Dendritic spines elongate after DHPG stimulation of group I mGluRs in cultured hippocampal neurons, possibly providing a substrate for synaptic depression (Vanderklish and Edelman, 2002). However, burst stimulation, under conditions in which group I mGluR responses are isolated, primes hippocampal synapses for subsequent induction of stable LTP (Cohen et al., 1998; Bortolotto et al., 1999; Raymond et al., 2000). Isolated versus synchronized $\mathrm{Ca}^{2+}$ elevations in astrocytes may therefore contribute to the direction of long-term synaptic changes via a mechanism involving group I mGluRs. In summary, astrocyte-to-neuron signaling in situ may occur by the activation of group I mGluRs to increase the probability of spontaneous glutamate release from neuronal presynaptic boutons, processes known to play a role in long-term synaptic plasticity.

\section{References}

Anderson CM, Swanson RA (2000) Astrocyte glutamate transport: review of properties, regulation, and physiological functions. Glia 32:1-14.

Anwyl R (1999) Metabotropic glutamate receptors: electrophysiological properties and role in plasticity. Brain Res Brain Res Rev 29:83-120.

Araque A, Parpura V, Sanzgiri RP, Haydon PG (1998) Glutamatedependent astrocyte modulation of synaptic transmission between cultured hippocampal neurons. Eur J Neurosci 10:2129-2142.

Araque A, Li N, Doyle RT, Haydon PG (2000) SNARE protein-dependent glutamate release from astrocytes. J Neurosci 20:666-673.

Beattie EC, Stellwagen D, Morishita W, Bresnahan JC, Ha BK, Von Zastrow M, Beattie MS, Malenka RC (2002) Control of synaptic strength by glial TNF $\alpha$. Science 295:2282-2285.

Bortolotto ZA, Fitzjohn SM, Collingridge GL (1999) Roles of metabotropic glutamate receptors in LTP and LTD in the hippocampus. Curr Opin Neurobiol 9:299-304.

Bushong EA, Martone ME, Jones YZ, Ellisman MH (2002) Protoplasmic astrocytes in CA1 stratum radiatum occupy separate anatomical domains. J Neurosci 22:183-189.

Cartmell J, Schoepp DD (2000) Regulation of neurotransmitter release by metabotropic glutamate receptors. J Neurochem 75:889-907.

Clark BP, Baker SR, Goldsworthy J, Harris JR, Kingston AE (1997) (+)-2Methyl-4-carboxyphenylglycine (LY367385) selectively antagonizes metabotropic glutamate mGluR1 receptors. Bioorg Med Chem Lett 7:2777-2780

Cohen AS, Raymond CR, Abraham WC (1998) Priming of long-term potentiation induced by activation of metabotropic glutamate receptors coupled to phospholipase C. Hippocampus 8:160-170.

Conti F, Weinberg RJ (1999) Shaping excitation at glutamatergic synapses. Trends Neurosci 22:451-458.

Diamond JS, Jahr CE (2000) Synaptically released glutamate does not overwhelm transporters on hippocampal astrocytes during high-frequency stimulation. J Neurophysiol 83:2835-2843.

Duan S, Anderson CM, Keung EC, Chen Y, Chen Y, Swanson RA (2003) $\mathrm{P} 2 \mathrm{X} 7$ receptor-mediated release of excitatory amino acids from astrocytes. J Neurosci 23:1320-1328.

Emptage NJ, Reid CA, Fine A (2001) Calcium stores in hippocampal synaptic boutons mediate short-term plasticity, store-operated $\mathrm{Ca}^{2+}$ entry, and spontaneous transmitter release. Neuron 29:197-208.

Fitzjohn SM, Pickard L, Duckworth JK, Molnar E, Henley JM, Collingridge GL, Noel J (2001a) An electrophysiological characterisation of longterm potentiation in cultured dissociated hippocampal neurones. Neuropharmacology 41:693-699.
Fitzjohn SM, Palmer MJ, May JE, Neeson A, Morris SA, Collingridge GL (2001b) A characterisation of long-term depression induced by metabotropic glutamate receptor activation in the rat hippocampus in vitro. J Physiol (Lond) 537:421-430.

Gasparini F, Lingenhohl K, Stoehr N, Flor PJ, Heinrich M, Vranesic I, Biollaz M, Allgeier H, Heckendorn R, Urwyler S, Varney MA, Johnson EC, Hess SD, Rao SP, Sacaan AI, Santori EM, Velicelebi G, Kuhn R (1999) 2-Methyl-6-(phenylethynyl)-pyridine (MPEP), a potent, selective and systemically active mGlu5 receptor antagonist. Neuropharmacology 38:1493-1503.

Gereau RW, Conn PJ (1995) Multiple presynaptic metabotropic glutamate receptors modulate excitatory and inhibitory synaptic transmission in hippocampal area CA1. J Neurosci 15:6879-6889.

Hanse E, Gustafsson B (2001) Vesicle release probability and pre-primed pool at glutamatergic synapses in area CA1 of the rat neonatal hippocampus. J Physiol (Lond) 531:481-493.

Herrero I, Miras-Portugal MT, Sanchez-Prieto J (1998) Functional switch from facilitation to inhibition in the control of glutamate release by metabotropic glutamate receptors. J Biol Chem 273:1951-1958.

Isaacson JS (2000) Spillover in the spotlight. Curr Biol 10:475-477.

Iwabuchi S, Kawahara K, Makisaka K, Sato H (2002) Photolytic flashinduced intercellular calcium waves using caged calcium ionophore in cultured astrocytes from newborn rats. Exp Brain Res 146:103-116.

Kimelberg HK, Goderie SK, Higman S, Pang S, Waniewski RA (1990) Swelling-induced release of glutamate, aspartate, and taurine from astrocyte cultures. J Neurosci 10:1583-1591.

Kovalchuk Y, Eilers J, Lisman J, Konnerth A (2000) NMDA receptormediated subthreshold $\mathrm{Ca}^{2+}$ signals in spines of hippocampal neurons. J Neurosci 20:1791-1799.

Kullmann DM (1999) Synaptic and extrasynaptic roles of glutamate in the mammalian hippocampus. Acta Physiol Scand 166:79-83.

Malgaroli A, Ting AE, Wendland B, Bergamaschi A, Villa A, Tsien RW, Scheller RH (1995) Presynaptic component of long-term potentiation visualized at individual hippocampal synapses. Science 268:1624-1628.

Manahan-Vaughan D, Reymann KG (1997) Group 1 metabotropic glutamate receptors contribute to slow-onset potentiation in the rat CAl region in vivo. Neuropharmacology 36:1533-1538.

McKinney RA, Capogna M, Durr R, Gahwiler BH, Thompson SM (1999) Miniature synaptic events maintain dendritic spines via AMPA receptor activation. Nat Neurosci 2:44-49.

Megias M, Emri Z, Freund TF, Gulyas AI (2001) Total number and distribution of inhibitory and excitatory synapses on hippocampal CA1 pyramidal cells. Neuroscience 102:527-540.

Nett WJ, Oloff SH, McCarthy KD (2002) Hippocampal astrocytes in situ exhibit calcium oscillations that occur independent of neuronal activity. J Neurophysiol 87:528-537.

Oertner TG, Sabatini BL, Nimchinsky EA, Svoboda K (2002) Facilitation at single synapses probed with optical quantal analysis. Nat Neurosci 5:657-664.

Parpura V, Haydon PG (2000) Physiological astrocytic calcium levels stimulate glutamate release to modulate adjacent neurons. Proc Natl Acad Sci USA 97:8629-8634.

Parpura V, Fang Y, Basarsky T, Jahn R, Haydon PG (1995) Expression of synaptobrevin II, cellubrevin, and syntaxin but not SNAP-25 in cultured astrocytes. FEBS Lett 377:489-492.

Parri HR, Gould TM, Crunelli V (2001) Spontaneous astrocytic Ca ${ }^{2+}$ oscillations in situ drive NMDAR-mediated neuronal excitation. Nat Neurosci 4:803-812.

Pasti L, Volterra A, Pozzan T, Carmignoto G (1997) Intracellular calcium oscillations in astrocytes: a highly plastic, bidirectional form of communication between neurons and astrocytes in situ. J Neurosci 17:7817-7830.

Pettit DL, Augustine GJ (2000) Distribution of functional glutamate and GABA receptors on hippocampal pyramidal cells and interneurons. J Neurophysiol 84:28-38.

Raymond CR, Thompson VL, Tate WP, Abraham WC (2000) Metabotropic glutamate receptors trigger homosynaptic protein synthesis to prolong long-term potentiation. J Neurosci 20:969-976.

Rodriguez-Moreno A, Sistiaga A, Lerma J, Sanchez-Prieto J (1998) Switch from facilitation to inhibition of excitatory synaptic transmission by group I mGluR desensitization. Neuron 21:1477-1486. 
Scanziani M, Salin PA, Vogt KE, Malenka RC, Nicoll RA (1997) Usedependent increases in glutamate concentration activate presynaptic metabotropic glutamate receptors. Nature 385:630-634.

Schneggenburger R, Neher E (2000) Intracellular calcium dependence of transmitter release rates at a fast central synapse. Nature 406:889-893.

Schwartz NE, Alford S (2000) Physiological activation of presynaptic metabotropic glutamate receptors increases intracellular calcium and glutamate release. J Neurophysiol 84:415-427.

Thomas LS, Jane DE, Gasparini F, Croucher MJ (2001) Glutamate release inhibiting properties of the novel $\mathrm{mGlu}(5)$ receptor antagonist 2-methyl6-(phenylethynyl)-pyridine (MPEP): complementary in vitro and in vivo evidence. Neuropharmacology 41:523-527.
Ullian EM, Sapperstein SK, Christopherson KS, Barres BA (2001) Control of synapse number by glia. Science 291:657-660.

Vanderklish PW, Edelman GM (2002) Dendritic spines elongate after stimulation of group 1 metabotropic glutamate receptors in cultured hippocampal neurons. Proc Natl Acad Sci USA 99:1639-1644.

Ventura R, Harris KM (1999) Three-dimensional relationships between hippocampal synapses and astrocytes. J Neurosci 19:6897-6906.

Ye ZC, Wyeth MS, Baltan-Tekkok S, Ransom BR (2003) Functional hemichannels in astrocytes: a novel mechanism of glutamate release J Neurosci 23:3588-3596.

Zhuo L, Sun B, Zhang CL, Fine A, Chiu SY, Messing A (1997) Live astrocytes visualized by green fluorescent protein in transgenic mice. Dev Biol 187:36-42. 